\title{
Contacts and Meetings: Location, Duration and Distance Traveled
}

\author{
Nebiyou Tilahun* $\quad$ David Levinson ${ }^{\dagger}$
}

Submission Date: August 1, 2009

*University of Minnesota, Department of Civil Engineering, tila0006@umn.edu

${ }^{\dagger}$ RP Braun-CTS Chair of Transportation Engineering; Director of Network, Economics, and Urban Systems Research Group; University of Minnesota, Department of Civil Engineering, 500 Pillsbury Drive SE, Minneapolis, MN 55455 USA, dlevinson@umn.edu http://nexus.umn.edu 


\begin{abstract}
The role of contacts on travel behavior has been getting increasing attention. This paper reports on data collected on individual's social meetings and the choice of in-home/out-ofhome meeting locations as well as the distance travelled and duration of out-home-meetings and its relationship to the type of contact met and other attributes of the meeting. Empirically we show that in-home meetings tend to occur most often with close contacts and less often with distant contacts. The purpose, meeting day, and household size suggest that leisure, weekend and large household size people tend to have their meetings either at their home or at their contact's home. In addition when meetings occur outside of the house, the duration is longer for close contacts and distance to the meeting location is directly influenced by duration and indirectly by the relationship type. Overall the paper illustrates that relationship type along with other meeting specific and demographic variables is important in explaining the location, duration and distance travelled for social meetings.
\end{abstract}




\section{Introduction}

The last few decades have shown increased interest in modeling individuals as travel makers and a departure from the aggregate four step process at least in academia. With the increasing focus on developing and implementing activity based travel models, it becomes increasingly important to document the different attributes that determine the frequency, duration, and location choices of the activities that people engage in. In this paper we focus on social meetings using a one week diary of a sample of individuals in the Minneapolis-St. Paul metropolitan area.

According to the 2001 National Household Travel Survey, on average social and recreational travel accounts for $24.5 \%$ of a household's annual distance travelled (1). As part decision makers of the social activities one engages in, their social contacts influence the location as well as duration of meeting decisions. These choices depend as much on whom one is meeting, their constraints on both space and time, as well as their preferences. It is plausible then that explicit consideration of who is involved in particular activities may shed more light on the choice of destinations and the allocation of time.

There is a growing recognition that social networks ought to be incorporated into an understanding of individual travel behavior. Axhausen (2) discusses how changes in the geography of social contacts along with changes in transport technologies could expand a persons activity space and account for increased travel. Other papers since then by him and colleagues have studied the size and geography of contacts and the communication mode between them $(3 ; 4)$ as well as proposed an agent model of the interdependence of social networks and travel(5) among others. Carrasco et al. (6) investigate the role of social networks in social-activity travel. Proposals for incorporating the social network paradigm into activity-travel behavior has also been made by Arentze and Timmermans (7).

Social meeting travel has much less structure than travel to work. Its frequency can vary significantly from person to person or even for the same person from week to week. It is dictated not only by the schedule of the traveller of interest but also by who else is involved in the meeting. Meeting location can vary from day to day, as can the time at which the meeting takes place. In fact, any structure that exists in social activity travel may come from the fixedness of working hours, employment locations, household constraints of the meeting parties and the operating hours of the meeting locations (when meetings occur outside the home) and the physical limitations that Hagerstrand (8) discusses. The consistency of work trips at the individual level that is shaped by employer policies is not present for social meetings. Consistency, when present, is a result of the indirect effect of other constraints and of preferences over meeting locations and convenience.

Advances in communication technologies add an interesting dimension to this complexity. Due to the instant access one has to an increasing number of contacts at all times of the day through mobile phones and other technologies, meetings can now be scheduled and rescheduled on short notice. Lower technological costs also mean more frequent interaction through these other media and that may lower the need for face-to-face meetings. Expanding communication possibilities also exist 
with higher bandwidth and the expanded use of video communications via computers.

While these technologies may alter how, when and with what frequency we interact, we are not at a point where face-to-face engagement is about to become a thing of the past. Dijst (9) sees the spread of these technologies reconfiguring the relationship between activities and places but not leading to the irrelevance of distance. Urry (10) also points out that technology works well for task oriented meetings while adding that co-present conversations are an essential part of social and economic life and key to the establishment of long term relations that require trust.

Spending "face time" with someone implies sharing the the totality of the environment at that moment and it does not appear that these technologies can create the same environment. Such interaction often takes longer, and is relaxed in the sense that there isn't a need for constant back and forth over the course of the meeting. Widely available technologies do not afford such an experience; first because, the parties are in two different environments, and second because they require either constant engagement over the duration of the communication (as in a phone conversation) or are asynchronous (as in email). In both cases, though to varying degrees, there is little chance of a shared experience in the moment that leads to new and sustained conversation as would happen in face-to-face meetings.

For workers, one can posit that a significant amount of structure to the times, duration and location of social meetings is imposed by the locations of home and work, and the time constraints placed by employment and household responsibilities. Countering these effects is the ability to free up time by using other technologies to interact with many others, and by the additional ability to organize meetings on very short notice. The ability to telecommute and having a flexible work schedule also loosen these constraints. The availability of multiple modes of communication at different costs allows users to pick and choose how they meet with different contacts. Here the type of relationship that one has with the contact influences meeting decisions such as where one meets (at home/out-of-home) and creates tradeoffs on how far one is willing to travel for a face-to-face meeting.

In this paper we focus on the location attributes (in-home/out-of-home) and the duration and distance travelled to meetings involving different types of contacts. The respondents we consider are all adult workers from whom data was collected using an internet based survey. In the following sections the survey and data are described. That will be followed by an analysis of in-home/out-ofhome meeting location decisions and their dependence on purpose and relationship type. Finally out-of-home meetings are studied by considering the dependence between relationship type, meeting duration, and home to meeting distance along with other demographic variables.

\section{Survey and Data}

Data for this study comes from a two phase web based survey that was administered to gather data on job finding, home finding, meetings that people participate and the social and technology networks that help them in these processes. Participants were recruited through mailed postcards. 
Postcards were sent to eight zip code areas in the Twin Cities to 5000 people in each of the two phases.The areas were chosen to have an economic and racial mix of respondents, as well as a city and suburban mix in the respondent pool. Reminder postcards were sent a week following the original mailing.

Survey participant had to be a working adults in the household. Invited respondents were asked to login to the survey with a unique code placed on the mailed postcard. The survey offered a $\$ 5.00$ coffee card to participants as well as a chance to be included in a drawing for an iPod Touch for one randomly selected respondent in each phase.

On first mailing 192 and 205 cards were returned due to wrong addresses from each phase. Overall there were 268 and 297 respondents in phase 1 and 2 respectively (5.88\% of postcards that reached their destination). The response rate for the survey was low and perhaps could have been increased by repeated solicitation to the respondents. In addition, because the questions went into the details of people's contacts and daily schedules, privacy concerns may have led some to drop out or skip questions. Availability of a computer and access to the internet in lower income areas may also have contributed to the low response rate.

Table 1 shows the distribution of demographic variables among the respondents and that for the State of Minnesota. Overall the sample shows bias towards women, and more highly educated individuals as compared to the demography of the State's population.

Broadly speaking, the survey focused on four areas. The first section dealt with the experience of the respondent during their last job search. Respondents were asked how they found their job, including whether contacts were used, and if so, details on the contact. The second section dealt with their residence, including when they moved and what their reasons for moving were, the third section dealt with the respondent's social network and what their weekly social meeting looks like and ends with questions about the respondent's commute and demographics.

\section{Data Summary}

The data for this portion of the study comes from the survey described in chapter ??. This section summarizes the data on meeting location, duration, purpose, relationship of the person that meetings took place with, and so on. In addition it examines how respondents use different communication media to maintain their relationships as well as schedule their meetings. The next section investigates the interrelationships among these variables and personal characteristics.

The analysis is limited to meetings that are local (happened within the metropolitan area). A one week meeting diary based on recall was collected from the participants of phase 2. Respondents were asked to "list all scheduled meetings you had in the last 7 days outside of your work location" and to include "all meetings with family, friends, get togethers, parties, civic engagements, meetings for personal/home related tasks, first time meetings, etc." There were 744 meetings from 222 respondents that took place within the metropolitan area. 
Table 1: Summary of Survey Subjects

\begin{tabular}{|l|l|l|l|}
\hline Variable & Group & Survey & Minnesota \\
\hline \multirow{2}{*}{ Sex } & Male & $39.8 \%$ & $49 \%$ \\
& Female & $60.2 \%$ & $51 \%$ \\
\hline Age & mean & 38.9 & 39.2 \\
\hline \multirow{2}{*}{ Household } & & & \\
\hline & Renter & $22.5 \%$ & $25.4 \%$ \\
& Owner & $77.4 \%$ & $74.6 \%$ \\
\hline \multirow{2}{*}{ Education } & Less than high school & $0.4 \%$ & $9.3 \%$ \\
(MN data for those 25 and older) & High school & $16.6 \%$ & $50.6 \%$ \\
& Associates degree & $14.1 \%$ & $9.6 \%$ \\
& Bachelor's degree & $45.7 \%$ & $20.8 \%$ \\
& Grad/Professional degree & $23.1 \%$ & $9.6 \%$ \\
\hline \multirow{2}{*}{ Household Income } & Mean & $\$ 76,550$ & $\$ 81,644$ \\
& Median & $\$ 68,000$ & $\$ 66,809$ \\
\hline \multirow{5}{*}{ Race } & White & $90.3 \%$ & $89.4 \%$ \\
& Black & $3.4 \%$ & $3.5 \%$ \\
& American Indian & $0.2 \%$ & $1.1 \%$ \\
& Asian & $3.2 \%$ & $2.9 \%$ \\
& Other & $3.0 \%$ & $3.1 \%$ \\
\hline
\end{tabular}

Just over a third of these meetings (33.9\%) occurred in-home, either at the respondent's residence or their contact's residence. The proportion of meetings that occur inside a home on weekdays is smaller than on weekends. Of 737 meetings for which location and date is known, in-home meetings make up $26.3 \%$ of weekday meetings, and $44.1 \%$ of weekend meetings. Weekday meetings are significantly more likely to be out-of-home than weekend meetings. During the weekend, $65 \%$ of meetings reported by single females were out-of-home, while $50 \%$ of meetings reported by single men were out-of-home. For multi-person households the figures are $45.9 \%$ for men and $46.9 \%$ for women. For weekday meetings on the other hand, $83.3 \%$ of meetings for single men occur out-of-home, $79.1 \%$ for single women, and $70.5 \%$ and $72.5 \%$ for men and women of multi-person households respectively.

Table 2 shows the average and median home to meeting distances on weekends on weekdays respectively. The first two columns and the last column only look at out-of-home meetings only. In general meetings tended to be closer to home than to work. When meetings take place at family/friends' homes on weekends, both the average and median distances were longer than the other categories. Meeting locations with family and friends, when they occur out-of-home, are similar to the overall weekday and weekend averages.

Over the period of seven consecutive days, many people had more than one meeting. The distribution of number of meetings per person is given in figure 1. The sudden drop from the number of people that had six meetings to those that had seven meetings might in part have been affected by 
Table 2: Distances for out-of-home meetings (mile)

\begin{tabular}{|l|c|c|c|c|}
\hline $\begin{array}{l}\text { Distance: } \\
\text { (mean/median) }\end{array}$ & $\begin{array}{c}\text { home to } \\
\text { meeting }\end{array}$ & $\begin{array}{c}\text { work to } \\
\text { meeting }\end{array}$ & $\begin{array}{c}\text { home to } \\
\text { friend's or } \\
\text { family home }\end{array}$ & $\begin{array}{c}\text { home to } \\
\text { meeting } \\
\text { (family/friend only) }\end{array}$ \\
\hline Weekday & $7.26 / 6.13$ & $9.5 / 7.93$ & $8.68 / 7.32$ & $7.20 / 5.89$ \\
$\mathrm{~N}$ & 349 & 334 & 161 & 44 \\
\hline Weekend & $7.59 / 6.34$ & $9.98 / 9.26$ & $13.25 / 12.03$ & $8.52 / 7.0$ \\
$\mathrm{~N}$ & 144 & 138 & 78 & 46 \\
\hline
\end{tabular}

the survey layout. Because responses for the seventh entry and on were on a second page, some of the respondents may have found it too demanding to fill out. This may mean that the analysis here underestimates the number of meetings that people make and that it may not capture the full geographic scale of the meeting locations. Despite this problem, we still have a large amount of information to analyze the location of meetings relative to the respondent's home and work.

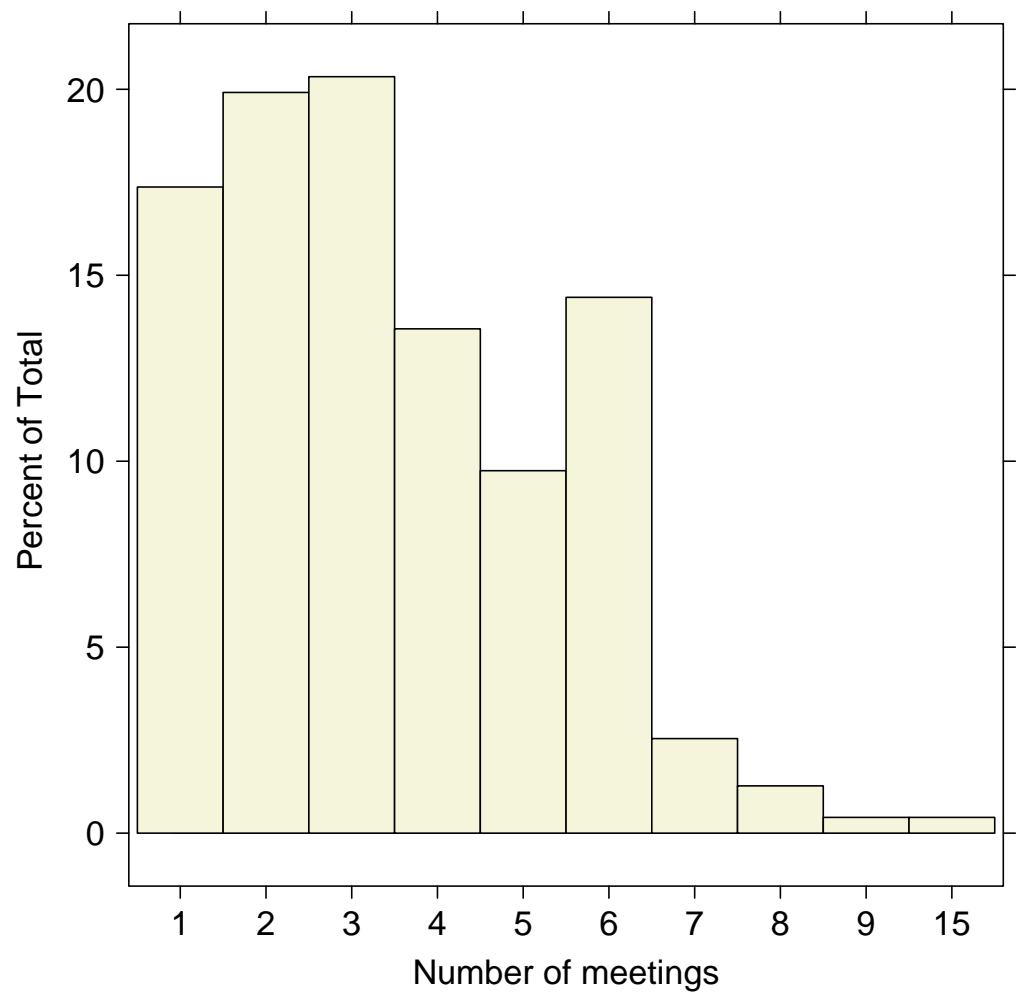

Figure 1: Number of meetings for respondents on the week prior to taking the survey

6 About half of the out-of-home meetings reported in the one week period are with close friends 7 (30.3\%) and family (18.1\%). These two groups also constitute $58.3 \%$ of all meetings (includ8 ing in-home meetings). The rest are divided between business coworkers and other contacts as 
Table 3: Proportion of meetings by contact relationship

\begin{tabular}{lll}
\hline Contact type & $\begin{array}{l}\text { Percentage of } \\
\text { all meetings }\end{array}$ & $\begin{array}{l}\text { Percentage of } \\
\text { out-of-home meetings }\end{array}$ \\
\hline Close friend & 33.21 & 30.32 \\
Family & 25.12 & 18.07 \\
Coworker & 7.48 & 10.04 \\
Business contact & 6.25 & 8.63 \\
Church Contact & 6.00 & 8.23 \\
Social club contact (book clubs etc.) & 4.90 & 5.22 \\
Distant Friend & 3.06 & 3.61 \\
Neighbor & 3.19 & 1.81 \\
More than one person & 4.90 & 6.22 \\
Other & 5.39 & 7.43 \\
Unreported & 0.49 & 0.40 \\
\hline & $100 \%$ & $100 \%$ \\
\hline
\end{tabular}

\title{
In-home and Out-of-home Meetings
}

shown in table 3 . Meetings that involve more than one person constituted $6.2 \%$ of all out-of-home meetings.

\begin{abstract}
Decisions on where to have a meeting depend on a variety of factors that have to do with the person's characteristics, circumstances of the meeting and the location of opportunities around them. In this section we will first investigate what motivates the in-home/out-of home decision for a meeting. It is assumed that in-home meetings are fundamentally different from even those meetings occurring very close to home. In-home meetings are generally with people one feels a stronger affinity to. A person may be comfortable inviting a contact to a neighborhood coffee shop but not necessarily into their homes.

In addition to the nature of the relationship between the meeting parties, whether a meeting occurs at home may be motivated by the purpose and anticipated duration of the meeting. It is expected that meetings at home would have longer durations. In addition, it is also expected that at leisure meetings are more likely to occur at home than other types of meetings.

Individuals that have more of their contacts close to their home are expected to have in home meetings more often than individuals with fewer friends close by. Household characteristics are also expected to be important. Larger households are expected to have more meetings at home than smaller ones.
\end{abstract}

A binomial logit model that predicts out-of-home meetings as a function of the personal characteristics and the meeting variables is specified as follows: 


$$
L \sim f\left(C_{r}, M, T_{m t}, F, Y_{h}, W, C_{p 3}, S, H\right)
$$

where

\section{$L$ : Location of meeting ( $1=$ out-of-home, $0=$ in-home)}

$C_{r}$ : The nature of the relationship (close contact vs. distant contact). Close relationships are those identified as family and close friend. (distant=1)

$M$ : Meeting purpose (1=leisure, $0=$ otherwise)

$T_{m t}$ : Meeting duration (in 10 minute increments)

$F$ : Does the person telecommute? (1=yes)

$Y_{h}$ : Tenure at home (years)

$W$ : Weekend (yes=1)

$C_{p 3}$ : Proportion of contacts in 3 miles of respondent's home

$S:$ Sex $($ male $=1)$

$E$ : Education ( $0=$ high school graduates, $1=$ above High school)

$H$ : Household size ( $1=$ single, $0=$ otherwise $)$

The estimated model is given in table 4 . The model captures the overall tendency to have meetings out of home rather than in-home in the intercept term. The nature of the relationship with whom the respondent is meeting has a significant influence on the location of the meeting. Meetings with close contacts were less likely to occur out of home as compared to meetings with less closer contacts. In the data about $58 \%$ of meetings were with close contacts - close friends, and family. Overwhelmingly close contacts tend to be met at home (or at their home). Seventy five percent of in-home meetings were with family or close friends. out-of-home meetings on the other hand are divided $48 \%$ to $53 \%$ as being with close and distant contacts respectively.

The meeting purpose is also closely associated with the meeting purpose. Compared to the base category of non-leisure meetings, leisure meetings were less likely to be outside of the home. Business or other purpose meeting tended to occur out side of the home.

It is assumed that people have a general idea of how long a meeting would take and would make location decisions accordingly. The findings weakly suggest that longer meetings take place at home (p-val=0.118). But as will be shown later, when considering out-of-home meetings separately, longer meeting durations are also associated with longer meeting distances. The tendency for longer duration of in-home meetings can also be explained by the fact that many of these are leisure meetings with close contacts, and are therefore less formal.

Approximately $31 \%$ of the respondents indicated they occasionally telecommute to work suggesting some level of flexibility on their work schedule. On average these individuals tend to have 
Table 4: Binomial logit model of in-home/out-of-home meeting choice (1=out-of-home, $0=$ inhome)

\begin{tabular}{|c|c|c|c|c|c|}
\hline & & Estimate & Std. Error & $\mathrm{z}$ value & $\operatorname{Pr}(>|\mathrm{z}|)$ \\
\hline (Intercept) & & 1.547 & 0.416 & 3.72 & $0.000 * * *$ \\
\hline Close relationship & $C_{r}$ & -0.553 & 0.219 & -2.53 & $0.011^{*}$ \\
\hline Meeting purpose & $M$ & -0.785 & 0.246 & -3.19 & $0.001 * *$ \\
\hline Meeting duration & $T_{m t}$ & -0.092 & 0.059 & -1.56 & 0.118 \\
\hline Telecommute? & $F$ & 0.515 & 0.217 & 2.37 & $0.018^{*}$ \\
\hline Home tenure & $Y_{h}$ & 0.029 & 0.013 & 2.22 & $0.027 *$ \\
\hline Weekend & $W$ & -0.673 & 0.191 & -3.52 & $0.000 * * *$ \\
\hline$\%$ contacts in $3 \mathrm{mi}$ & $C_{p 3}$ & 0.670 & 0.529 & 1.27 & 0.205 \\
\hline Sex & $S$ & 0.160 & 0.208 & 0.77 & 0.442 \\
\hline Education & $E$ & 0.688 & 0.255 & 2.70 & $0.007 * *$ \\
\hline House & $H$ & -0.196 & 0.070 & -2.81 & $0.005 * *$ \\
\hline \multicolumn{2}{|c|}{ Null deviance } & 797.11 & \multicolumn{2}{|c|}{$\mathrm{df}=644$} & \\
\hline \multicolumn{2}{|c|}{ Residual deviance } & 697.15 & \multicolumn{2}{|c|}{$\mathrm{df}=634$} & \\
\hline \multicolumn{2}{|c|}{ Psuedo- $R^{2}$} & 0.125 & & & \\
\hline \multicolumn{2}{|c|}{$* * *<0.001$} & $* *<0.01$ & $*<0$. & & 0.1 \\
\hline
\end{tabular}

Table 5: Predictive accuracy of in-home/out-of-home meeting model

\begin{tabular}{rrr}
\hline & Predicted probabilities \\
& $<.5$ & $\geq .5$ \\
\hline In-home & 59 & 140 \\
Out-of-home & 45 & 401 \\
\hline
\end{tabular}

meetings outside of the home as compared to their counterparts that responded they don't telecommute. Tenure at home is also significantly associated with in-home meetings.

The model also illustrates that weekend meetings as well as meetings of people with larger households tend to happen in-home relative to weekday meetings and the meetings of single households respectively. Finally those with college level education tend to have more meetings out of home relative to those with high school level education.

The $C_{p 3}$ variable, which measures the proportion of contacts that live in 3 miles of the respondent's residence is not statistically significant in predicting meeting location ( $\mathrm{p}$-val=0.205). Sex is also found not to matter in deciding whether a meeting is in-home or out-of-home.

Overall the model categorizes $71.3 \%$ of the observations as happening in-home or out-of-home correctly (Table 5). However, it falsely predicts in-home meetings as being out-of-home in many instances. The model also suffers because information on the parties being met, whom one can assume had as much contribution as the individuals being considered here, is lacking. 


\section{Out-of-home Meetings}

For this part of the study we shall focus on meetings that occur outside of the respondent's or their contact's residence. It is hypothesized that the choice of out-of-home locations depends on the individual and their household constraints, as well as on who they are meeting including the nature of the relationship. Expectations on the duration of the meeting, and the availability of possible meeting locations in the neighborhood in which the individual lives is also expected to influence the meeting location. The interdependence of many of these variables on each other (e.g. personal variables on duration and distance, distance on duration, etc.) call for an integrated model where the structure of the data and the interdependence can be studied.

Duration and distance decisions are likely to be interrelated. For scheduled meetings, it is hypothesized that individuals would be willing to travel longer distances for longer duration meetings. Since meetings would revolve around some purpose whose duration one is likely to anticipate before hand, the meeting location decision is likely to be affected by it. The decision would try to balance duration and distance, as well as balance duration with other household and individual constraints. Weekend meetings for example are likely to be longer, just because work constraints on time are not present. Larger household sizes are likely to lead to shorter durations because of other household responsibilities on the person's time allocation.

A path model is proposed where the effects of different variables and their covariance is modeled explicitly. Path analysis has its origins in biology in the work of Sewall Wright $(11 ; 12 ; 13 ; 14)$. Wright (15) describes path analysis as:

“...a way of dealing with interrelated variables. It is based on the construction of qualitative diagram in which every included variable, measured or hypothetical, is represented (by arrows) either as completely determined by certain others (which may be represented as similarly determined) or as an ultimate factor."

The method is one where a hypothesized set of relationships that are dependent on one another can be tested. Path models employ both standardized and absolute (measured) variables in estimation. For the standardized estimates, each of the variables is adjusted so that its mean is zero and its standard deviation is equal to one. The standardized estimates of the path model give how many standard deviations the endogenous variable moves in response to a change in one standard deviation of the exogenous variable when all other variables are held constant. The regression coefficients, estimated from the observed variables, measure the contribution of each of the independent variables on the dependent variables. The method has often been called causal modeling, however, as Denis and Legerski (16) point out the case for causality has to lie outside of the statistical modeling technique. Miller (17) summarizes the assumptions behind path models.

Figure 2 presents the proposed model. Meeting duration is proposed to depend on age, education, household size, income, relationship and meeting purpose, while the home to meeting distance is proposed to depend on the relative quality of the respondent's home neighborhood in terms of available meeting destinations, the availability of vehicles, the flexibility of their schedules as well as demographic characteristics of the respondent. 


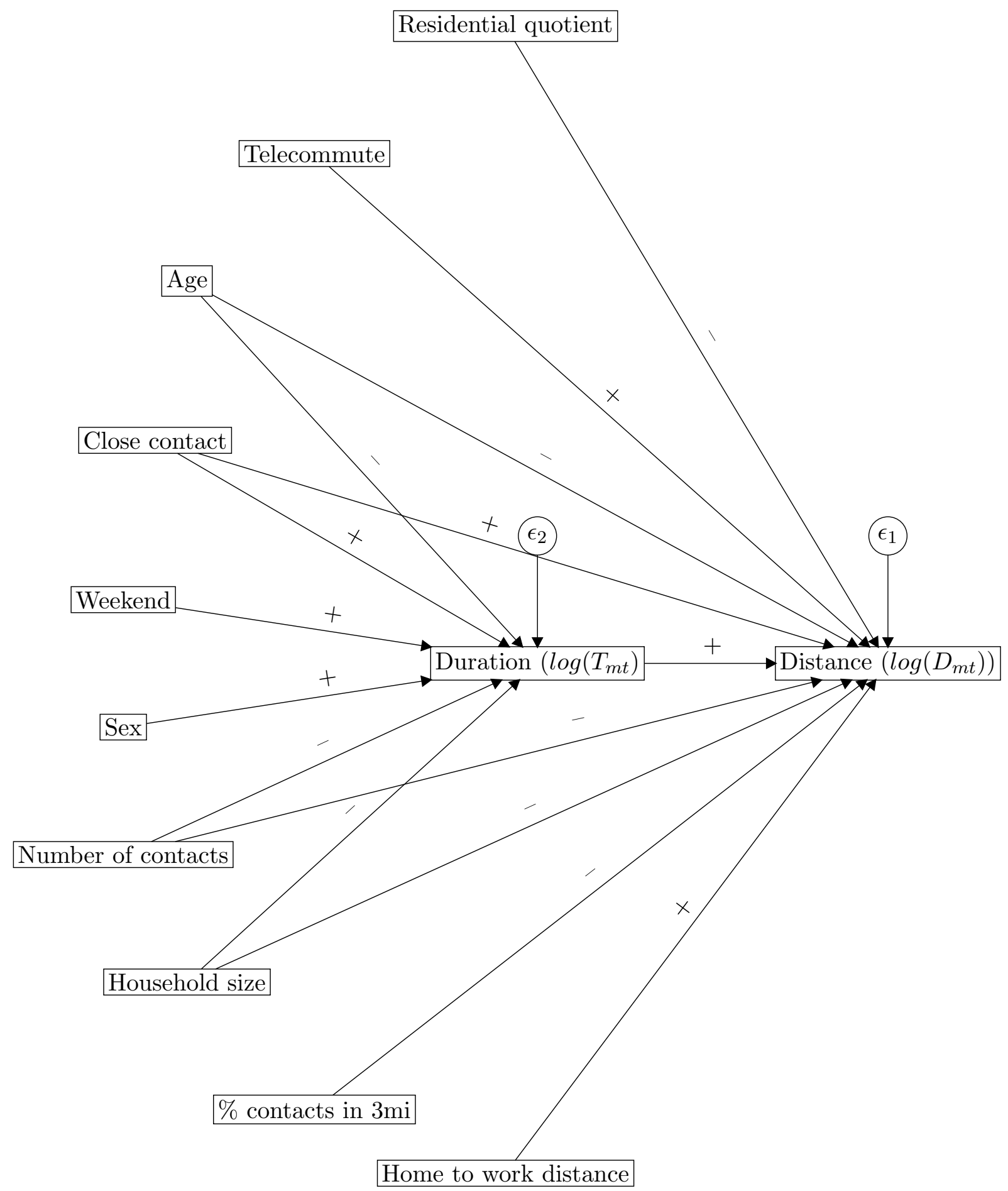

Figure 2: A path model of meeting distances and meeting duration for out-of-home meetings(correlations between trip variables are not shown) 
The relative availability of destinations is measured as the ratio of the proportion of entertainment, food, and retail businesses in the residential blockgroup of the respondent, to the aggregate proportion of such businesses businesses in the metropolitan area. This number is less than 1 if the blockgroup has a lower proportion of these businesses, which can serve as meeting locations, relative to the metropolitan area. This is similar to how location quotients are calculated in economic base modeling. Here the number of businesses in a particular sector are used to calculate the quotient. Values greater than one indicate that relative to the metropolitan area the residence blockgroup of the respondent has a higher share of businesses that are focused on retail, food and entertainment.

The variables included in the final path model are:

$L$ : Location of meeting ( $1=$ out-of-home, $0=$ in-home)

$D_{m t}$ : The home to meeting location distance.

$T_{m t}$ : Meeting duration (in 10 minute increments)

$C_{r}$ : The nature of the relationship (close contact vs. distant contact). Close relationships are those identified as family and close friend. (distant=1)

$F$ : Does the person telecommute? (1=yes)

$W$ : Weekend (yes=1)

$H$ : Household size (1=single, 0 otherwise)

A: Age of the respondent

$V:$ Number of household vehicles

$Q$ : Neighborhood quotient, measuring if the respondent's block group has a higher proportion of food, entertainment, and retail businesses as compared to the metropolitan area as a whole.

Model fitting is done using the SAS/CALIS software (18). The goodness of fit measures for the model are given in table 6 . The estimated path coefficients and correlations are summarized in tables 7 and 8 . The chi-squared measure in table 6 compares the covariance matrix from the estimated model with the observed model. A large p-value is evidence that the estimated covariance closely resembles the observed relationships in the model (failure to find a statistical difference). None of the adjusted residuals exceeded a value of 1.2 in absolute value. Values of 0.9 and above in the NFI and NNFI indices indicate that the model provides an acceptable fit. Table 9 summarizes the overall and indirect effects of the exogenous variables in our model on meeting duration and home to meeting distance. Figure 3 shows the relationships between the variables using standardized path coefficients (i.e. these are similar to the coefficients that would be estimated if all variables in the model were standardized so that they have mean 0 and variance of 1 ).

Based on the analysis, the proposed model has been readjusted to reflect the best fit. For instance the link between age and meeting duration, number of contacts and distance as well as percentage 
of contacts in 3 miles and duration has been removed from the proposed model (figure 2). The $R^{2}$ values for the duration and meeting distance indicate the amount of variance in that is accounted for by the direct paths. The models suggest that even though the impact of the variables included suggests clear trends, there is still significant variance left in the model to address. But this is expected to some degree as meeting decisions are also affected by the meeting parties that are not included in this analysis, and can also easily be influenced by variables such as the "mood" of the person on that particular day etc. that are difficult to capture based on observed variables.

The path model suggests that age has a negative influence on distance. The older one is the less they travel to meet others. While not statistically significant, telecommuters tend to travel farther for meetings, and those that have a relatively higher concentration of retail and entertainment businesses with in their residential blockgroup tend to travel less for meetings. This is likely because of the ample number of destinations that can be used as out-of-home meeting locations. People who have a larger percentage of their close contacts within three miles of their home also have shorter home to meeting distances. Household size and home to work distance both impact meeting duration positively. A possible reason for why larger household size individuals have longer meeting distances could be that they have meetings just after work, or as they run other errands outside of the home. On meeting duration, larger household sizes tend to shorten meeting durations as expected.

Home to meeting distances also increase with home to work distances positively. For each $10 \%$ increase in-home to meeting location, the home to meet distance increased by $1.3 \%$. This suggests that the neighborhood around the work location is also an important meeting area. Coworkers make up $10 \%$ of out-of-home meetings and it is reasonable to expect at least many of the meetings with them and others are centered around the work location.

\begin{tabular}{rrrrrr}
\multicolumn{7}{c}{ Table 6: Goodness of Fit of Measures } \\
& Chi-squared & df & p & NFI & NNFI \\
\hline Null Model & 244.43 & 66 & 0.000 & - & - \\
Estimated Model & 6.34 & 10 & 0.786 & 0.974 & 1.135 \\
\hline
\end{tabular}

Meeting duration on the other hand is significantly influenced by the type of relationship, the household size, gender and meeting day. Meetings with close relationships are expected to take about 34\% longer all other things the same. Weekend meetings are also 19\% longer, and men tended to have longer meetings than women by 7.4\%. Larger household sizes have shorter meetings. The trend in the number of contacts suggests that larger social contact circle individuals tends to have longer meetings.

Longer durations are associated with higher distances travelled. A 10\% increase in meeting duration, increases the distance one travels for the meeting by $1.1 \%$. The impact of duration on distances implies that the variables having a direct impact on duration have an indirect impact on distance. These effects are given in Table 9. The indirect impact of having close relationship with the contact, a weekend meeting and being male is positive. On the other hand household size has an indirect negative impact on distance through its impact on reducing meeting duration. Overall 


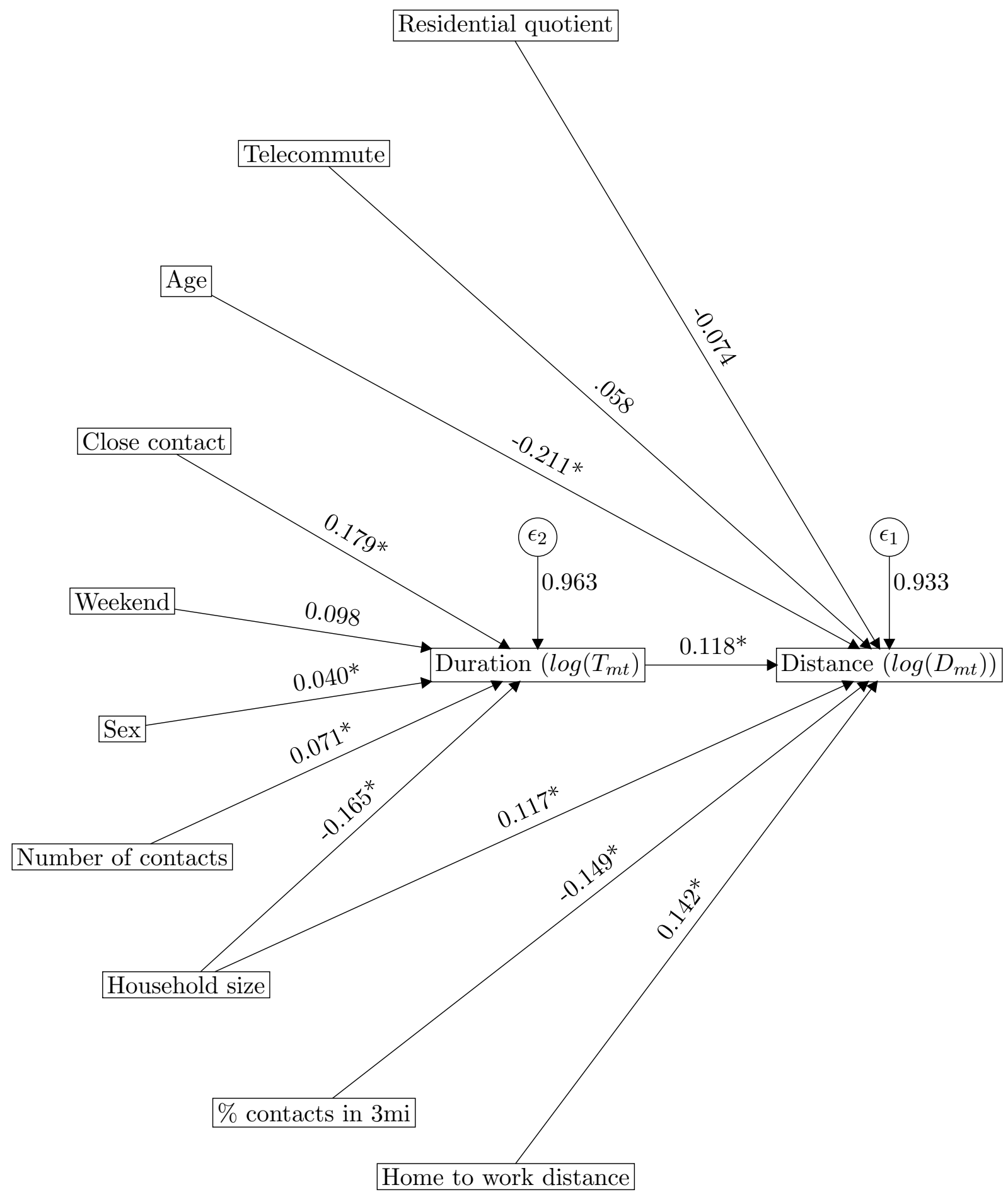

Figure 3: A path model of meeting distances and meeting duration for out-of-home meetings. Estimates are based on standardized data. See table 8 for correlation among independent variables. 
Table 7: Estimated path model for meeting duration and home to meeting distance

\begin{tabular}{|c|c|c|c|c|c|}
\hline & & Variable & Estimate & Std. Error & t-stat \\
\hline \multirow{10}{*}{$\begin{array}{r}\text { Home to } \\
\text { meeting } \\
\text { distance } \\
\left(\log \left(D_{m t}\right)\right)\end{array}$} & Meeting duration & $\log \left(T_{m t}\right)$ & 0.114 & 0.049 & 2.341 \\
\hline & Home to work distance & $\log \left(D_{h w}\right)$ & 0.134 & 0.048 & 2.797 \\
\hline & Age & $A$ & -0.014 & 0.003 & -4.149 \\
\hline & Household size & $H$ & 0.072 & 0.03 & 2.442 \\
\hline & Telecomute (flexibility) & $F$ & 0.094 & 0.082 & 1.148 \\
\hline & Residence quotient & $Q$ & -0.102 & 0.072 & -1.407 \\
\hline & $\%$ of contacts in $3 \mathrm{mi}$ & $\widetilde{C}_{p 3}$ & -0.006 & 0.002 & -2.795 \\
\hline & Error variance & & 0.541 & & \\
\hline & Total variance & & 0.622 & & \\
\hline & $R^{2}$ & & 0.13 & & \\
\hline \multirow{8}{*}{$\begin{array}{l}\text { Meeting } \\
\text { duration } \\
\log \left(T_{m t}\right)\end{array}$} & Close relationship & $C_{r}$ & 0.291 & 0.084 & 3.481 \\
\hline & Household size & $H$ & -0.105 & 0.035 & -3.036 \\
\hline & Weekend & $W$ & 0.174 & 0.091 & 1.906 \\
\hline & Number of contacts $(/ 10)$ & $C$ & 0.037 & 0.028 & 1.311 \\
\hline & $\operatorname{Sex}(1=$ male $)$ & $S$ & 0.072 & 0.03 & 2.442 \\
\hline & Error variance & & 0.613 & & \\
\hline & Total variance & & 0.661 & & \\
\hline & $R^{2}$ & & 0.073 & & \\
\hline
\end{tabular}

though its net effect of household size on distance is positive.

\section{Summary}

This paper reports on data collected on individual's social meetings and the choice of in-home/outof-home meeting locations. In addition, out-of-home meetings are analyzed by looking at the dependence between demographic characteristics and characteristics of the meeting on meeting duration, as well as the effect of duration and different socio-demographic variables on distance travelled for the meetings. In general we find that the type of relationship, the meeting purpose and the individual's demographic background have some role to play. Mainly we have shown that in-home meetings tend to occur most often with close contacts and less often with distant contacts. The purpose, meeting day, and household size suggest that leisure, weekend and large household size people tend to have their meetings either at their home or at their contact's home. On the other hand less known contacts are met outside of the home. When meetings occur outside of the house, the duration is longer for close contacts, for men and is decreases with increasing household size. Distance to the meeting location is directly influenced by duration and indirectly by the relationship type. People with larger household sizes and longer home to work distances also have longer distances perhaps indicating meetings occur closer to work. Older individual travel shorter distances for meetings. Persons who have a larger proportion of their contacts in a 
Table 8: Correlations among independent variables of the path model

\begin{tabular}{|l|l|r|}
\hline Variable 1 & Variable 2 & Correlation \\
\hline$Q$ & $C_{p 3}$ & 0.298 \\
$C_{p 3}$ & $S$ & -0.124 \\
$C_{r}$ & $A$ & -0.153 \\
$\log \left(D_{h w}\right)$ & $C_{p 3}$ & -0.175 \\
$A$ & $W$ & 0.105 \\
$A$ & $F$ & 0.163 \\
$H$ & $C$ & 0.329 \\
$C_{r}$ & $F$ & -0.103 \\
\hline
\end{tabular}

Table 9: Total and indirect effects of model variables on meeting distance and duration

\begin{tabular}{|l|l|r|r|r|}
\hline \multicolumn{2}{|l|}{} & \multicolumn{2}{|c|}{ Total Effects } & Indirect Effects \\
\hline & & $\log \left(D_{m t}\right)$ & $\log \left(T_{m t}\right)$ & $\log \left(D_{m t}\right)$ \\
\hline $\log \left(D_{h w}\right)$ & Home to work distance & 0.134 & & \\
$C_{r}$ & Close relationship & 0.033 & 0.291 & 0.033 \\
$A$ & Age & -0.014 & & \\
$H$ & Household size & 0.06 & -0.105 & -0.012 \\
$W$ & Weekend & 0.02 & 0.174 & 0.02 \\
$F$ & Telecomut & 0.094 & & \\
$Q$ & Residence quotient & -0.102 & & \\
$C_{s}$ & Number of contacts (/10) & 0.004 & 0.037 & \\
$C_{p 3}$ & \% of contacts in 3 mi & -0.006 & & 0.004 \\
$S$ & Sex (1=male) & 0.008 & 0.072 & \\
$\log \left(T_{m t}\right)$ & Meeting duration & 0.114 & & 0.008 \\
\hline
\end{tabular}

3 mile radius of their home also tend to travel shorter distances, while the availability of meeting locations (land-use) does not significantly reduce the home the meeting location distance. Overall the paper has shown that relationship type and a persons size of social networks are important variables in explaining both the location, duration and distance travelled for social meetings. 


\section{References}

[1] Pat Hu and Timothy Reuscher. Summary of Travel Trends 2001 National Household Travel Survey. Technical report, U.S. Department of Transportation, Federal Highway Adminstration, Washington, D.C., 2004.

[2] K.W. Axhausen. A dynamic understanding of travel demand: A sketch. Arbeitsberichte Verkehrs-und Raumplanung, 119, 2002.

[3] K.W. Axhausen, A. Frei, and T. Ohnmacht. Networks, biographies and travel: First empirical and methodological results. In 11th International Conference on Travel Behaviour Research, Kyoto, August, available from the author, 2006.

[4] K.W. Axhausen and A. Frei. Contacts in a shrunken world. In 86th Annual Meeting of the Transportation Research Board, Washington, D.C., 2008.

[5] J.K. Hackney and K.W. Axhausen. An agent model of social network and travel behavior interdependence. In 11th International Conference on Travel Behaviour Research. Kyoto, 2006.

[6] J.A. Carrasco, E.J. Miller, and B. Wellman. Spatial and Social Networks: The Case of Travel for Social Activities. In 11th International Conference on Travel Behaviour Research, Tokyo, Japan, August, pages 16-20, 2006.

[7] T. Arentze and H. Timmermans. Social networks, social interactions, and activity-travel behavior: a framework for microsimulation. Environment and Planning B: Planning and Design, 35(6):1012-1027, 2008.

[8] T. Hagerstrand. What about people in regional science. Papers of the Regional Science Association, 24:7-21, 1970.

[9] M. Dijst. "ICT and social networks towards a situational perspective on the interaction between corporeal and connected presence". The Expanding Sphere of Travel Behaviour Research Ed. R Kitamura (Emerald, New York) forthcoming, 2009.

[10] John Urry. Social networks, travel and talk. British Journal of Sociology, V54(2):155-175, 2003.

[11] S Wright. The relative importance of heredity and environment in determining the piebald pattern of guinea-pigs. Proceedings of the National Academy of Sciences, 6:320-332, 1920.

[12] S Wright. Correlation and causation. Journal of Agricultural Research, Jan 1921.

[13] S Wright. The theory of path coefficients a reply to niles's criticism. Genetics, Jan 1923.

[14] S Wright. The method of path coefficients. The Annals of Mathematical Statistics, 5(3):161215, 1934.

[15] Sewall Wright. Path coefficientes and path regressions: Alternative or complementary concepts? In Hubert M. Blalock, editor, Causal Models in the Social Sciences, chapter 3, pages 
39-53. Aldine Transaction, 1985. Reproduced from S. Wright, "Path Coefficientes and Path Regressions: Alternative or Complementary Concepts?" Biometrics 16 (1960).

[16] D Denis and J Legerski. Causal modeling and the origins of path analysis. Theory \& Science, Jan 2006.

5 [17] M Miller. Potentials and pitfalls of path analysis: A tutorial summary. Quality and Quantity, 6 Jan 1977.

7 [18] SAS Institute Inc. Sas 9.1.3. Cary, NC, 2000-2004. 